\title{
Pituitary Adenoma Associated With Rathke's Cleft Cyst: Report of 15 Cases
}

\author{
Wenhao Wu, Guijun Jia, Wang Jia, Guilin Li, Junting Zhang, Liwei Zhang
}

\begin{abstract}
Objective: The concomitant presence of pituitary adenoma (PA) with Rathke's cleft cyst (RCC) is rare, and most of the literature published is case reports. RCC's clinicopathological features have not been well described. Methods: We retrospectively reviewed the data of 15 patients with PA associated with RCC. We also provide a systematic review of the literature. Results: The patients included males and seven females. The transsphenoidal approach was adopted for all patients except one, who underwent right frontal craniotomy. Complete resection was achieved in nine cases, with grossly complete resection in five and partial removal in one. Of the PA subtypes available, five patients had nonfunctional pituitary adenomas, three had multiple-hormone secreting PAs, three had prolactin-producing adenomas, and one had a growth hormone-secreting adenoma. All of the patients' symptoms and abnormal endocrine test results resolved or were relieved after surgery. The mean follow-up time was $27.6 \pm 16.6$ months. All of the patients recovered well and had no signs of recurrence during their follow-up, except for one patient. Conclusions: A cyst-like signal indicated on images or cystic materials encountered during operation in a patient with PA suggest the possibility of PA associated with RCC. Transsphenoidal surgery is the preferred approach and can resolve or relieve patients' symptoms to a great extent. Histologically, nonfunctional PA and prolactinoma are the most common types of PA coexisting with RCC; the mechanisms of PA associated with RCC need to be investigated further.

RÉSUMÉ: Des adénomes hypophysaires associés à des kystes de la poche de Rathke : 15 cas rapportés. Objectif: La présence concomitante d'adénomes hypophysaires (AP) et de kystes de la poche de Rathke (KPR) demeure inhabituelle. La plupart des travaux de recherche publiés sur le sujet l'ont été sous forme d'études de cas. On peut aussi ajouter que les caractéristiques cliniques et pathologiques des KPR n'ont pas été très bien décrites jusqu'à maintenant. Méthodes: Nous avons révisé de façon rétrospective les données de 15 patients chez qui l'on avait diagnostiqué des AP associés à des KPR. Nous avons également procédé à une recension systématique des écrits sur le sujet. Résultats: Huit patients étaient de sexe masculin; sept d'entre eux, de sexe féminin. Hormis un patient, chez qui l'on a pratiqué une craniotomie frontale sur le côté droit, une intervention par voie transsphénoïdale a été privilégiée pour tous les autres patients. Une résection complète a été effectuée chez neuf patients alors qu'on a plutôt procédé à une résection largement complète chez cinq d'entre eux et à une élimination partielle chez un seul. Parmi tous les sous-types d'AP détectés, cinq patients étaient atteints d'AP non fonctionnels ; trois, d'AP sécrétant de multiples hormones ; trois, d'adénomes produisant de la prolactine; un, d'un adénome produisant des hormones de croissance. Tous les symptômes des patients ont disparu ou ont été soulagés à la suite de la chirurgie mentionnée ci-dessus. De plus, aucun test du système endocrinien ne s'est révélé anormal par la suite. La période de suivi des patients a été en moyenne de 27,6 16,6 mois. À l'exception d'un seul d'entre eux, tous se sont bien rétablis et n'ont montré aucun signe de récidive durant leur période de suivi. Conclusions: Des signaux indiquant la présence d'un kyste à la suite d'examens d'imagerie, de même que des tissus kystiques trouvés lors d'une intervention chirurgicale chez un patient atteint d'AP, suggèrent la possibilité que les AP soient associés aux KPR. Une intervention chirurgicale par voie transsphénoïdale demeure l'approche à privilégier car elle peut faire disparaître ou soulager dans une grande mesure les symptômes des patients atteints. D'un point de vue histologique, les AP non fonctionnels et les prolactinomes sont les types d'AP qui coexistent le plus souvent avec les KPR. Enfin, les mécanismes liant les AP aux KPR devront être examinés de façon plus approfondie.
\end{abstract}

Keywords: histopathology, imaging, pituitary adenoma, Rathke's cleft cyst, surgery

doi:10.1017/cjn.2017.252

Can J Neurol Sci. 2018; 45: 68-75

Pituitary edema (PA) and Rathke's cleft cyst (RCC) are both common and benign sellar lesions; however, they rarely occur together. In a large study series involving 782 patients with known $\mathrm{PA}$, the rate of concomitant RCC was $0.51 \%{ }^{1}$ According to a recent report, eight cases $(1.46 \%)$ with dual sellar pathology were histologically diagnosed among 548 cases with PA, and only two concomitant RCCs were identified $(0.74 \%){ }^{2}$ According to our review of the literature, most of the articles were case reports that lack long-term follow-up and comprehensive review. There is considerably less knowledge regarding PA concomitant with $\mathrm{RCC}$, and the clinicopathological characteristics have not been well described. Here, we report 15 patient cases with the aim of analyzing the clinical, radiological, surgical, histological, and prognostic characteristics of these coexisting lesions. The analysis is presented with a review of the literature to systematically investigate the clinicopathological features of these collision lesions.

From the Department of Neurosurgery, Beijing Tiantan Hospital, Capital Medical University, Beijing, China (WW, GJ, WJ, JZ, LZ); China National Clinical Research Center for Neurological Diseases. Beijing, China (WW, GJ, WJ, JZ, LZ); Department of Neuropathology, Beijing Neurosurgical Institute, Capital Medical University, Beijing, China

(GL); Center of Brain Tumor, Beijing Institute for Brain Disorders, Beijing, China (GL).

Received January 28, 2017. Final Revisions Submitted August 2, 2017. Date of Acceptance August 4, 2017.

Correspondence to: Liwei Zhang, Department of Neurosurgery, Beijing Tiantan

Hospital, Capital Medical University, China National Clinical Research Center for

Neurological Diseases, No.6 Tiantan Xili, Dong Cheng District, Beijing 100050, China.

Email: zhlwttyy@163.com 


\section{METHODS}

This study was approved by the Institutional Review Board of Beijing Tiantan Hospital. We retrospectively studied the medical histories, physical examination results, imaging results, operative findings, and histological examinations of the 15 patients with PA and concomitant RCC. The RCCs were grossly unruptured. All 15 patients were treated at Beijing Tiantan Hospital between 2009 and 2016. All patients were preoperatively and postoperatively evaluated with endocrine testing and magnetic resonance imaging (MRI). The endocrine testing includes prolactin (PRL), growth hormone $(\mathrm{GH})$, insulin-like growth factor, follicle-stimulating hormone, luteinizing hormone, adrenocorticotropic hormone (ACTH), thyroid-stimulating hormone, and so on. The resected tumor specimens were evaluated by experienced pathologists to make a histological diagnosis to ensure a functional classification of the PAs could be performed. The follow-up results included changes in clinical symptoms, enhanced MRI scan results, and endocrine testing.

For our literature review, an advanced search in PubMed for English articles was carried out. The key words used were "adenoma" and "Rathke's," which were entered into the title/ abstract field to search the related literature as comprehensively as possible. The search yielded 128 results from 1981 to 2016; among these results, 23 English-language articles were identified that reported on patients involving a PA associated with RCC.

\section{Results}

\section{Preoperative History}

The clinical data for the 15 patients are available in Table 1. The patients were eight males and seven females. Their mean age was $48.1 \pm 12.4$ years (range, 20-67 years). Headache and visual disabilities were the most common symptoms. The clinical manifestations of the functional PAs depended on the hormone secreted and could present as a menstrual disorder, galactorrhea, or acromegaly. One patient was diagnosed with tumor recurrence; she had had transsphenoidal surgery 1 year previous. There were no hypothalamic dysfunction or increased intracranial pressure reports in this group. The course of illness ranged from 15 days to 10 years.

\section{Radiological Findings}

Computed tomography and MRI were performed for each patient preoperatively. Of the PAs, two were microadenomas diagnosed on dynamic contrast-enhanced scan of the sellar region with MRI. The others were macroadenomas. The tumors were mainly located in the intra- and suprasellar areas, except for four cases that involved the parasellar region. Among these cases, two were grade 3 on the Knops scale, whereas the other two were grade 4 . The typical imaging of PA associated with RCC was that a cyst-like signal with no contrast enhancement was indicated on MRI with an obvious PA, and the cyst was usually enclosed by the PA or adjacent to the adenoma, as shown in case 3 (Figure 1). However, it was occasionally difficult to identify the two different signal intensities between the PA and RCC, as indicated in case 1 (Figure 2). The 15 patients were all initially diagnosed with PAs or PAs with cystic change or apoplexy of PAs.

\section{Surgical Results}

Based on the clinical and radiological findings, a transsphenoidal approach was adopted for all patients except one, who

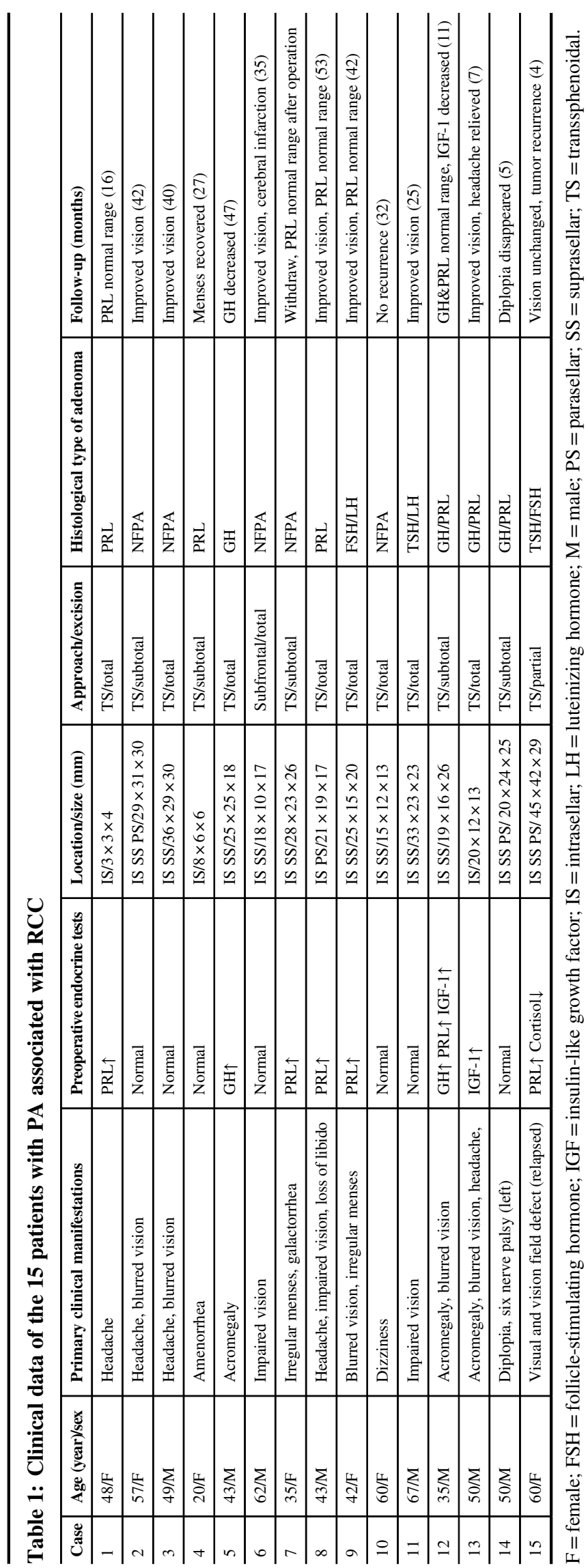



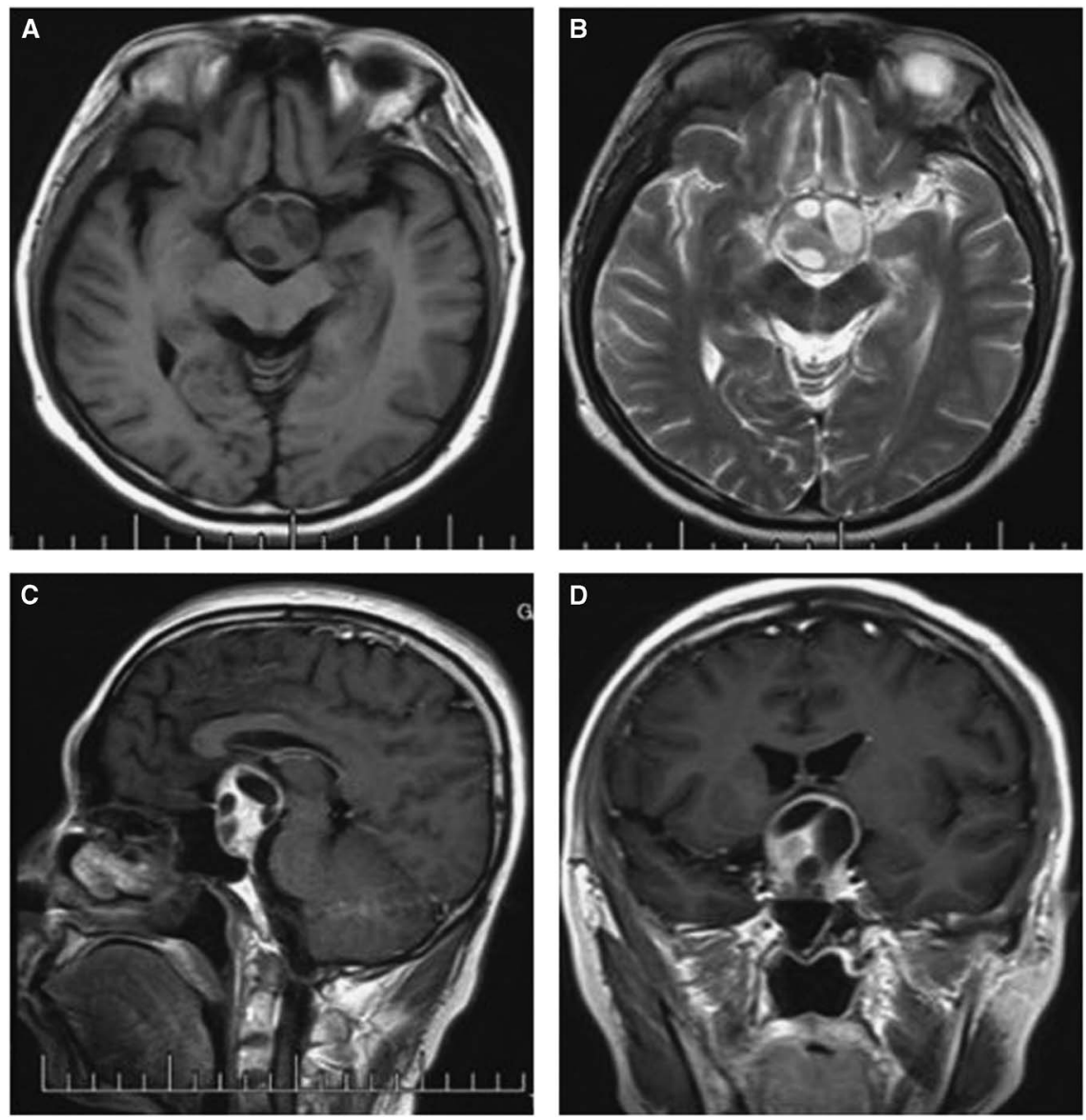

Figure 1: Preoperative and postoperative MRI scans of case 3. Axial T2-weighted (A) images showing an isointense mass in the sellar region with multicystic lesions inside; Contrastenhanced sagittal $(B)$ and coronal $(C)$ images show obvious enhancement of the solid mass and no changes in the cysts, with the tumor extending into the suprasellar area. The postoperative images show the tumor was totally removed and there was a hemorrhage at the site of the operation $(D-F)$.

underwent right frontal craniotomy. Complete removal was achieved in nine cases, whereas subtotal resection was achieved in five and partial removal in one. During surgery, clear yellow fluid was observed in three patients and mucinous and colloidal materials were encountered in five patients.

After surgery, the patients' headaches were relieved and their vision improved. A computed tomography scan on the first day after surgery indicated that there was a hemorrhage at the site of the operation in cases 3 and 15. Conservative management and surgical clearance was adopted, respectively. The hematoma was stable and partially absorbed at the time of discharge. Postoperative endocrine evaluation indicated that the patients' PRL and GH levels returned to the normal range or decreased compared with preoperative levels. Additionally, some of the patients demonstrated mild or moderate thyroid dysfunction and transient electrolyte disturbance and were thus given symptomatic and supportive treatment.

\section{Pathological Findings}

Microscopically, the tumor contained two components. The first component was monomorphic cells with round or oval nuclei containing stippled chromatin. The second component showed fragments of a cyst wall lined by simple cuboidal or pseudostratified ciliated columnar epithelium; the lumen of the cyst contained an abundance of myxoid materials (Figure 3A). Immunohistochemical analysis demonstrated positive results for PRL and GH/PRL in three patients (Figure 3B-C). A positive result for GH staining was indicated in one patient. There was no obvious staining in the other five cases, which were diagnosed as nonfunctional PAs (NFPAs) associated with RCC. Additionally, positive expression of cytokeratin in $8 / 18$ cases was observed.

\section{Follow-up}

Fourteen patients continued their follow-up; one patient was lost to follow-up. The median follow-up period was $27.6 \pm 16.6$ months (4-53 months). Among the 14 patients, 13 had no obvious abnormality of endocrine testing, and their MRI examinations showed no evidence of recurrence. Case 15 suffered from tumor recurrence and increased PRL level during the follow-up. Case 4's menses returned but was still irregular. Case 5 did not undergo MRI examination and had no obvious symptoms. In case 6 , the patient suffered from cerebral infarction 15 days after discharge with mild neurological defects. 

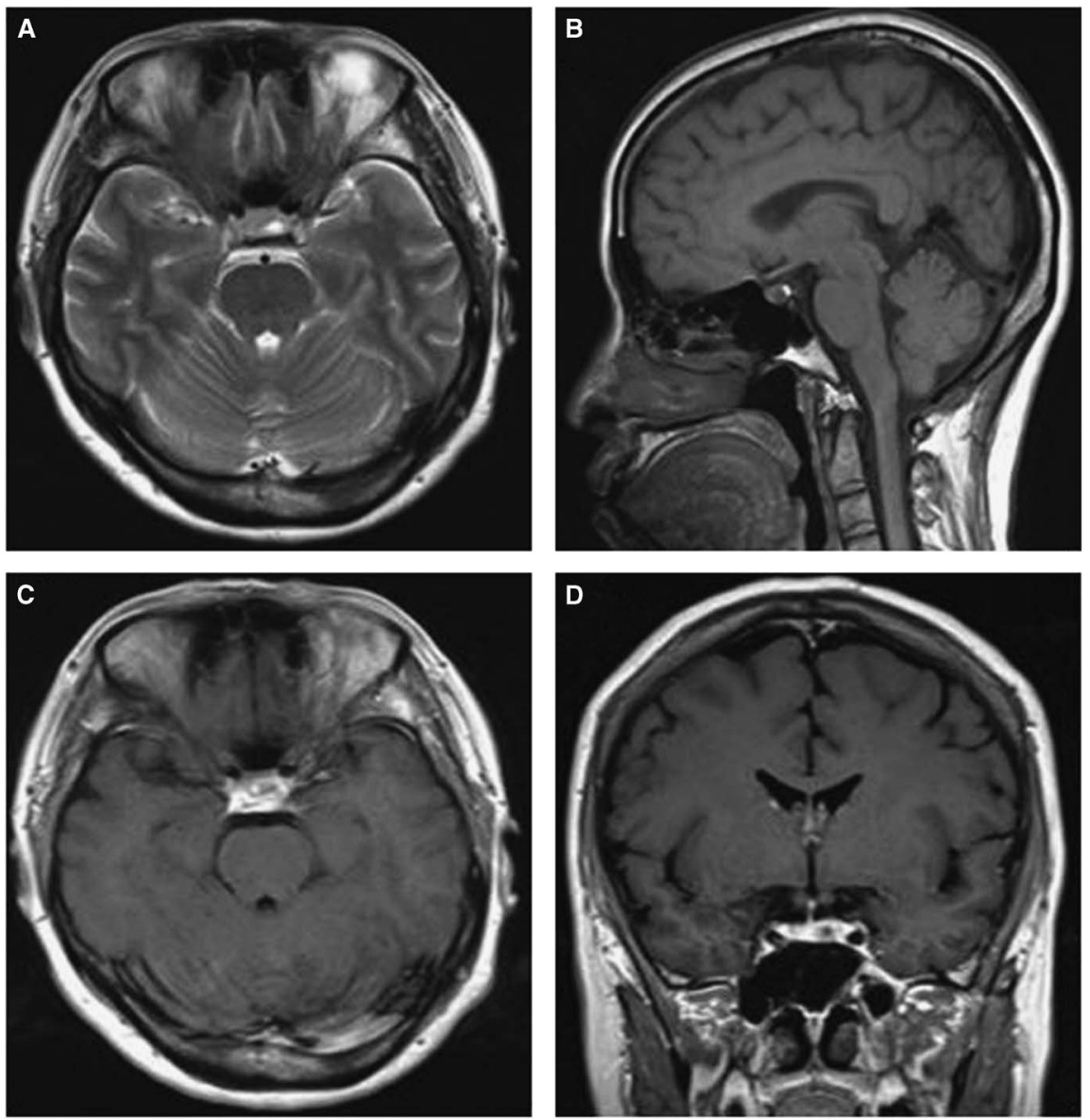

Figure 2: Preoperative and postoperative MRI scans of case 1. Axial T2-weighted (A) images revealing uneven signal intensity in the pituitary measuring approximately $4 \mathrm{~mm}$ in greatest diameter. (B) A contrast-enhanced sagittal image showing obvious enhancement of the pituitary, but identifying two different entities was difficult. (C) Dynamic contrast-enhanced image demonstrating a delayed-enhancement region on the left of the pituitary, with the pituitary stalk displaced slightly to the right; The postoperative images showed the tumor was resected completely $(D-F)$.

\section{Literature Analysis}

The 23 reports published from 1985 to 2016 in PubMed were reviewed, and only 59 cases of PA and concomitant RCC were included. The clinicopathological characteristics of the patients are summarized in Table 2. There were 17 males and 24 females, and they varied in age from 16 to 76 years (median, 42 years). The most common complaints varied from patient to patient and can be classified as endocrine symptoms and mass effect generally. From our review, the former occurred more often than the latter.
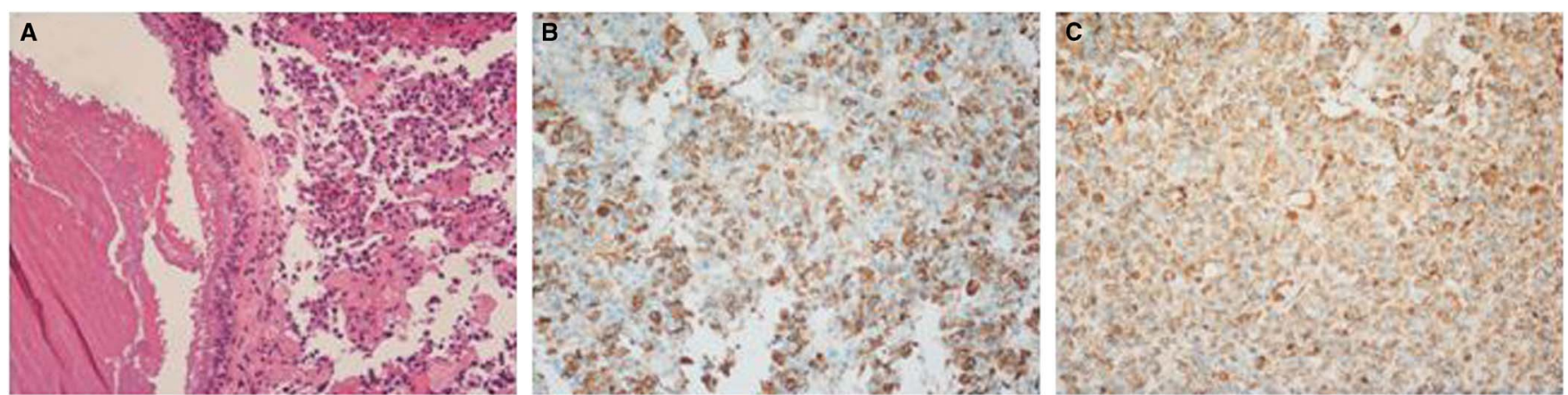

Figure 3: Hematoxylin-eosin and immunohistochemical findings for case 12. (A) Clusters of uniform PA cells with mucin-filled cyst. The cyst was lined by ciliated columnar epithelium $(\times 200)$. (B) Immunostaining of GH was positive in the adenoma cells $(\times 200)$. (C) PRL staining of adenoma cells showed strong reactivity $(\times 200)$. 
Table 2: Clinical data of the reported cases with PA associated with RCC

\begin{tabular}{|c|c|c|}
\hline Characteristic & No. of patients $(\%)$ & Total* \\
\hline Age (year) & & 41 \\
\hline Median (range) & $42(16-76)$ & \\
\hline Mean $( \pm$ SD $)$ & $42.5 \pm 15.5$ & \\
\hline Gender & & 41 \\
\hline Male & $17(41.5)$ & \\
\hline Female & $24(58.5)$ & \\
\hline Primary clinical presentations & & 41 \\
\hline Headache & $6(14.6)$ & \\
\hline Decreased vision & $5(12.2)$ & \\
\hline Visual field defect & $5(12.2)$ & \\
\hline Acromegaly & $13(31.7)$ & \\
\hline Menstrual disorder & $13(31.7)$ & \\
\hline Galactorrhea & $8(19.5)$ & \\
\hline Cushing's disease & $6(14.6)$ & \\
\hline Other & $10(24.4)$ & \\
\hline Preoperative endocrine tests & & 37 \\
\hline $\operatorname{PRL} \uparrow$ & $14(37.8)$ & \\
\hline $\mathrm{GH} \uparrow$ & $11(29.7)$ & \\
\hline $\mathrm{ACTH} \uparrow$ & $5(13.5)$ & \\
\hline Normal & $2(5.4)$ & \\
\hline Other & $5(13.5)$ & \\
\hline Location & & 45 \\
\hline IS & $15(33.3)$ & \\
\hline IS SS & $27(60.0)$ & \\
\hline IS PS/SS & $3(6.7)$ & \\
\hline Histological type of adenoma & & 55 \\
\hline PRL & $16(29.1)$ & \\
\hline NFPA & $14(25.5)$ & \\
\hline GH & $12(21.8)$ & \\
\hline ACTH & $8(14.5)$ & \\
\hline Other & $5(9.1)$ & \\
\hline
\end{tabular}

*Only patients with required data were included.

$\mathrm{SD}=$ standard deviation

Most of the tumors were located at the intra- and suprasellar region (93.3\%), as observed on MRI. Occasionally, the tumor invaded into the parasellar area $(6.7 \%)$. All of the patients underwent surgical resection via a transsphenoidal approach, except for four patients who required right frontal craniotomy. Among the 55 patients with histological data, 16 patients had prolactin-producing adenomas, 14 had NFPAs, 12 had GHsecreting adenomas, 8 had ACTH-secreting adenomas, and 2 had mixed adenomas. Additionally, three patients were classified using traditional hematoxylin-eosin staining. Surgical results were available for 32 patients. Most of the patients recovered uneventfully, and their hormonal imbalances were corrected. Three patients experienced hypopituitarism after their operation, and hormone replacement therapy was administered. Three patients experienced diabetes insipidus, which was well controlled with medication. One patient suffered from cerebrospinal fluid rhinorrhea, which subsided after lumbar drainage combined with transsphenoidal sellar floor repair. There was no long-term follow-up.

\section{Discussion}

The coexistence of PA with RCC has rarely been reported and is seldom encountered in clinical practice. To our knowledge, only 59 patients have been identified among 23 English articles. ${ }^{1-23}$ According to our review, there was a slight female predominance to the co-incidence of these lesions. The male-tofemale ratio was approximately $0.7: 1$; however, there were more male patients than female patients in our case series. This may be the result of a limited number of patients. The clinical manifestations were mainly dependent on the hormone secreted and the size of the tumor. Endocrine symptoms such as amenorrhea, galactorrhea, acromegaly, and Cushing's disease were usually caused by PAs. Further, with increasing tumor size, compressive signs or symptoms appeared, including headache, visual diminution, vision field defects, and so on. The literature review indicates that the endocrine symptoms occur more often than compressive symptoms. This is different from our patients. In our series, many cases had macroadenoma or even giant adenoma associated with RCC with supra- or parasellar extension, which contributes to mass effect.

A preoperative diagnosis of PA associated with RCC is difficult because most cases are clinically and radiologically similar to PAs; this is true especially for microadenoma of the pituitary and atypical cysts. Most of the diagnoses were based on histological results. In our group, two cases were diagnosed as microadenomas of the pituitary associated with RCC. The diagnosis of microadenoma itself is relatively difficult, and even MRI scans may yield negative results. The diagnosis depends on the combination of clinical symptoms, imaging results, and endocrine testing to achieve a comprehensive determination. Thus, the diagnosis of microadenoma of PA associated with RCC is more challenging. It is usually difficult to distinguish the two lesions on MRI scans. RCC may have a variable imaging appearance on MRI images depending on the cyst composition. ${ }^{24}$ The presence of mucinous fluid, hemosiderin deposition, and hemorrhage within the cyst contribute to the MRI characteristics. ${ }^{13}$ RCCs do not usually demonstrate contrast enhancement or show thin cyst wall enhancement, whereas PAs are characterized by homogeneous enhancement. When a cyst-like signal is observed on MRI scans in a patient with PA, the possibility of coexisting RCC should be considered.

Surgical resection and decompression represent the most effective treatment. Transsphenoidal surgery is performed for most reported cases, including our 14 patients. Both solid tissue and cystic material can be observed in some cases, and a probable diagnosis of PA associated with RCC can be made. However, any clear yellow fluid should not be mistaken for cerebrospinal fluid leakage caused by rupture of the sellar diaphragm. Compared with macroadenoma of the pituitary associated with RCC, microadenoma combined with RCC is more challenging both with respect to the preoperative diagnosis and the surgical resection. Because of the small tumor volume, the localization of a microadenoma coexisting with an RCC is difficult during the operation. 
Intraoperative navigation can help to determine the exposure range of the sellar floor and the location of the tumor, which is important for total resection and functional protection. ${ }^{25}$ Surgery can resolve or relieve patients' symptoms to a great extent; however, the biochemical remission rates are greatly dependent on tumor size and depth of invasion. ${ }^{5}$ Surgical results are satisfactory for most patients both in our series and literature, including our two cases with microadenoma of pituitary combined with RCC. After surgery, one patient's PRL level returned to normal range and the other patient's endocrine symptoms were relieved. These two patients were discharged uneventfully and recovered well. At times, it is not easy to achieve gross total resection if the tumor has invaded the cavernous sinus. In this case, radical removal is not recommended to avoid serious complications, and adjuvant therapy such as radiotherapy may be used. Intraoperative MRI scans can assist with complete resection and provide excellent information on these two different disease entities. ${ }^{12}$ For the cyst itself, simple drainage of the contents with partial removal of the cyst wall is usually adequate and reduces the risk of pituitaryhypothalamic dysfunction, visual complications, and aseptic meningitis. $^{26,27}$

The histological subtype of the PAs was confirmed by immunohistochemical staining. In total, taking the reported 55 cases and adding our 12 cases with histological subtypes, there were 19 NFPAs, 19 prolactinomas, $13 \mathrm{GH}$ adenomas, eight ACTH adenomas, and five mixed adenomas. The other three cases were classified as chromophobe or eosinophilic adenomas. Among them, the data on age, gender, symptoms, and location were available in 36 patients. The characteristics of different types of PA concomitant with RCC are shown in Table 3. Most of the NFPAs associated with RCC presented with mass effect, whereas functional PAs with RCC showed endocrine symptoms. This may indicate that the symptoms of these collision lesions are mainly caused by the PAs. The NFPAs and GH adenomas coexisting with RCC are mainly located at intra- and suprasellar region, whereas ACTH adenomas with RCC are predominately located at intrasellar area. Histological examinations showed that the tumors had two different components. The major component was uniform and polygonal adenoma cells arranged in sheets and nests; the other cystic space was lined by epithelial cells. The cyst wall was typically composed of simple cuboidal or ciliated columnar epithelium and mucous-secreting cells that were pathognomonic for RCC. ${ }^{8,10}$ Occasionally, the RCCs were partially or completely lined by stratified squamous epithelium or had squamous metaplasia, which is also a characteristic of craniopharyngioma. In such cases, the lack of a solid component and the presence of extensive ciliation and/or mucin production suggested the possibility of RCC. ${ }^{28}$ The cyst contents were usually a thick, mucoid material consisting of cholesterol and protein, which in surgical series have been described as yellowish (15\%-37\%), mucoid (51\%-70\%), or gelatinous (10\%). ${ }^{29}$ Immunohistochemical analysis was helpful for classifying PAs and diagnosing RCC. The positive expression of cytokeratin can be used to differentiate RCCs from other lesions. ${ }^{30}$ In our cases, there were two patients with microadenoma of the pituitary and concomitant RCC. The preoperative diagnosis of microadenoma coexisting with $\mathrm{RCC}$ was very difficult. Most of the diagnosis was based on histological results; therefore, the histological examinations were very important. After hematoxylin-eosin and immunohistochemical staining, the two patients were diagnosed as PRL adenoma associated with RCC.

The development of RCC appears simple. The residual lumen of the pouch is reduced to the narrow Rathke's cleft, which is usually obliterated completely. Failure to obliterate the lumen results in the development of RCC. For PA, similar to other tumors, the pathogenic mechanisms are very complex and still unclear. The development of PAs is thought to involve the interaction of multiple factors, including genetic defects, environmental factors, and endocrine alterations. ${ }^{31,32}$ The coexistence of PA and RCC has been investigated previously, but the pathological mechanisms remain controversial. There is a notion that Rathke's pouch proliferates to form the anterior pituitary lobe, from which PAs develop ${ }^{33}$; therefore, RCC derived from the remnants of Rathke's pouch and PAs may have a shared origin. Kepes $^{34}$ reported the transitional cell tumor of the pituitary gland developing from an RCC. The cells corresponded to an early developmental stage of the pituitary anterior lobe, when the still squamous and columnar Rathke's cleft cells began to develop their endocrine granulation. Thus, the tumor was derived from "transitional" cells between the lining cells of Rathke's cleft and the glandular cells of the anterior pituitary; however, this theory was questioned by Ikeda et al, ${ }^{6}$ who proved that the cyst within a PA differed from cyst found in the embryonic stage of the pituitary gland. Trokoudes et $\mathrm{al}^{35}$ reported that the pathogenesis of

Table 3: Features of different types of PA concomitant with RCC

\begin{tabular}{l|c|c|c|c|c|c|c|c|c}
\hline Type of PA & No. & Age* & \multicolumn{2}{|c|}{ Gender } & \multicolumn{2}{c}{ Symptoms } & \multicolumn{3}{c}{ Location } \\
\hline & & (year) & M & F & ME & ES & IS & IS SS & PS \\
\hline PRL & 4 & 38.8 & 2 & 2 & 2 & 2 & 2 & 1 & 1 \\
\hline NFPA & 15 & 47.3 & 7 & 8 & 13 & 6 & 3 & 9 & 3 \\
\hline GH & 7 & 44.7 & 3 & 4 & 2 & 7 & 1 & 5 & 1 \\
\hline ACTH & 5 & 43.0 & 3 & 2 & 1 & 5 & 4 & 1 & 0 \\
\hline PRL + GH & 5 & 41.2 & 4 & 1 & 4 & 4 & 1 & 3 & 1 \\
\hline Other & 3 & 56.3 & 1 & 2 & 3 & 1 & 0 & 2 & 1 \\
\hline Total & 39 & - & 20 & 19 & 25 & 25 & 11 & 21 & 7 \\
\hline
\end{tabular}

*Average.

$\mathrm{ES}=$ endocrine symptom; $\mathrm{ME}=$ mass effect $\mathrm{PS}=$ parasellar. 
concurrent prolactinoma and RCC derives from prolactin cell stimulation by an existing RCC, resulting in secondary adenoma formation; however, this theory was rejected by Maria et $\mathrm{al}^{2}$ because it contradicts the monoclonal origin of PAs. Furthermore, such a theory cannot be applied to other types of PA combined with an RCC. Karavitaki et al ${ }^{7}$ considered that the coexistence of the lesions may be entirely coincidental. Although these coexisting lesions could be considered purely incidental events, such a coincidence seems to be less plausible based on their common histological origin and the number of cases presented in literature. Most recently, Ikeda et al ${ }^{36}$ indicated that a ruptured RCC contributed a risk factor of PA, with a high incidence of $34 \%$. The authors also pointed out that six of 203 (3\%) patients with PA had an associated RCC in their retrospective study. We speculate that an existing RCC is a risk factor of PA; and the ruptured RCC is more likely associated with PA compared with unruptured RCC. However, the mechanisms underlying PA associated with RCC are very complex and may include inflammatory stimulation, histogenetic factors, endocrine effects, and so on. The pathogenesis of PA associated with RCC remains to be clarified.

In summary, the coexistence of PA and RCC is rare. It is usually difficult to make a diagnosis before surgery. When a nonenhancing cyst-like signal is demonstrated on MRI scans in a patient with PA, the possibility of a coexisting RCC should be considered. Transsphenoidal surgery is the recommended treatment approach for most patients, and a satisfactory result can be achieved. Although PA and RCC have common embryological origins, the pathological mechanisms of their coexistence need to be investigated further.

\section{ACKNOWLEDGMENTS}

This work was supported by grants from the National Key Technology Research and Development Program of Ministry of Science and Technology of China (2015BAI12B04) and the Basic-clinical Cooperation Project of Capital Medical University (1150170156).

\section{Disclosures}

The authors do not have anything to disclose.

\section{STATEMENT OF AUTHORSHIP}

WW sorted the data and wrote the paper; GJ and WJ were responsible for data collection and interpretation; GL contributed to the histopathology of the paper; JZ revised the paper critically; and LZ was responsible for conception, design, and final appraisal for publication.

\section{REFERENCES}

1. Noh SJ, Ahn JY, Lee KS, Kim SH. Pituitary adenoma and concomitant Rathke's cleft cyst. Acta Neurochir (Wien). 2007;149:1223-8.

2. Koutourousiou M, Kontogeorgos G, Wesseling P, Grotenhuis AJ, Seretis A. Collision sellar lesions: experience with eight cases and review of the literature. Pituitary. 2010;13:8-17.

3. Arita K, Uozumi T, Takechi A, et al. A case of Cushing's disease accompanied by Rathke's cleft cyst: the usefulness of cavernous sinus sampling in the localization of microadenoma. Surg Neurol. 1994;42:112-6.

4. Babu R, Back AG, Komisarow JM, Owens TR, Cummings TJ, Britz GW. Symptomatic Rathke's cleft cyst with a co-existing pituitary tumor; Brief review of the literature. Asian J Neurosurg. 2013;8:183-7.
5. Bader LJ, Carter KD, Latchaw RE, Ellis WG, Wexler JA, Watson JC. Simultaneous symptomatic Rathke's cleft cyst and GH secreting pituitary adenoma: a case report. Pituitary. 2004;7:39-44.

6. Ikeda H, Yoshimoto T, Katakura R. A case of Rathke's cleft cyst within a pituitary adenoma presenting with acromegaly-do "transitional cell tumors of the pituitary gland" really exist? Acta Neuropathol. 1992;83:211-5.

7. Karavitaki N, Scheithauer BW, Watt J, et al. Collision lesions of the sella: co-existence of craniopharyngioma with gonadotroph adenoma and of Rathke's cleft cyst with corticotroph adenoma. Pituitary. 2008;11:317-23.

8. Miyagi A, Iwasaki M, Shibuya T, et al. Pituitary adenoma combined with Rathke's cleft cyst-case report. Neurol Med Chir (Tokyo). 1993;33:643-50.

9. Nakasu S, Nakasu Y, Kyoshima K, Watanabe K, Handa J, Okabe H. Pituitary adenoma with multiple ciliated cysts: transitional cell tumor? Surg Neurol. 1989;31:41-8.

10. Nishio S, Fujiwara S, Morioka T, Fukui M. Rathke's cleft cysts within a growth hormone producing pituitary adenoma. Br J Neurosurg. 1995;9:51-5.

11. Nishio S, Mizuno J, Barrow DL, Takei Y, Tindall GT. Pituitary tumors composed of adenohypophysial adenoma and Rathke's cleft cyst elements: a clinicopathological study. Neurosurgery. 1987;21:371-7.

12. Radhakrishnan N, Menon G, Hingwala DR, Radhakrishnan VV. Non-functioning pituitary adenoma and concomitant Rathke's cleft cyst. Indian J Pathol Microbiol. 2011;54:649-51.

13. Sumida M, Migita K, Tominaga A, Iida K, Kurisu K. Concomitant pituitary adenoma and Rathke's cleft cyst. Neuroradiology. 2001;43:755-9.

14. Swanson SE, Chandler WF, Latack J, Zis K. Symptomatic Rathke's cleft cyst with pituitary adenoma: case report. Neurosurgery. 1985; 17:657-9.

15. Vancura RW, Jacob KM, Damjanov I. A 70-year-old man with diplopia, nausea, and vomiting. Rathke cleft cyst concomitant with pituitary adenoma. Arch Pathol Lab Med. 2006;130:403-4.

16. Wang K, Ma L, You C. Pituitary adenoma and concomitant Rathke's cleft cyst: a case report and review of the literature. Neurol India. 2012;60:309-10.

17. Yamakita N, Ikeda T, Murai T, et al. Panhypopituitarism due to Rathke's cleft cyst associated with pituitary oncocytoma. Intern Med. 1997;36:107-12.

18. You C, Qiao F, Jiang S, Xiao A. Growth hormone secreting pituitary adenoma associated with Rathke's cleft cyst. Neurol India. 2012;60:310-1.

19. Zhou P, Cai B, Ma W, Jiang S. Combined pituitary adenoma and Rathke's cleft cysts: two multicystic cases and literature review. Neurol India. 2012;60:665-7.

20. Gessler F, Coon VC, Chin SS, Couldwell WT. Coexisting Rathke cleft cyst and pituitary adenoma presenting with pituitary apoplexy: report of two cases. Skull Base Rep. 2011;1:99-104

21. Tamura R, Takahashi S, Emoto K, Nagashima H, Toda M, Yoshida K. GH-Producing pituitary adenoma and concomitant Rathke's cleft cyst: a case report and short review. Case Rep Neurol Med. 2015;2015:948025.

22. Guo SY, Cai XQ, Ma J, Wang WY, Lu G. Diagnosis of concomitant pituitary adenoma and Rathke's cleft cyst with magnetic resonance imaging. Int J Surg. 2015;18:191-5.

23. Gao M, An Y, Huang Z, et al. The coexistence of Rathke cleft cyst and pituitary adenoma. J Craniofac Surg. 2016;27:e128-30.

24. Valassi E, Biller BM, Klibanski A, Swearingen B. Clinical features of nonpituitary sellar lesions in a large surgical series. Clin Endocrinol (Oxf). 2010;73:798-807.

25. Hitier M, Hibon R, Candelier G, Guarnieri J, Moreau S, Babin E. The uses of computer-assisted surgical navigation in trans-nasal pituitary gland surgery. Rev Laryngol Otol Rhinol (Bord). 2009;130:151-7.

26. Shin JL, Asa SL, Woodhouse LJ, Smyth HS, Ezzat S. Cystic lesions of the pituitary: clinicopathological features distinguishing craniopharyngioma, Rathke's cleft cyst, and arachnoid cyst. J Clin Endocrinol Metab. 1999;84:3972-82.

27. Xie T, Hu F, Yu Y, Gu Y, Wang X, Zhang X. Endoscopic endonasal resection of symptomatic Rathke cleft cysts. J Clin Neurosci. 2011;18:760-2. 
28. Karavitaki N, Cudlip S, Adams CB, Wass JA. Craniopharyngiomas. Endocr Rev. 2006;27:371-97.

29. Trifanescu R, Ansorge O, Wass JA, Grossman AB, Karavitaki N. Rathke's cleft cysts. Clin Endocrinol (Oxf). 2012;76:151-60.

30. Xin W, Rubin MA, McKeever PE. Differential expression of cytokeratins 8 and 20 distinguishes craniopharyngioma from rathke cleft cyst. Arch Pathol Lab Med. 2002;126:1174-8.

31. Rostad S. Pituitary adenoma pathogenesis: an update. Curr Opin Endocrinol Diabetes Obes. 2012;19:322-7.

32. Vandeva S, Tichomirowa MA, Zacharieva S, Daly AF, Beckers A. Genetic factors in the development of pituitary adenomas. Endocr Dev. 2010;17:121-33.
33. Trifanescu R, Stavrinides V, Plaha P, et al. Outcome in surgically treated Rathke's cleft cysts: long-term monitoring needed. Eur J Endocrinol. 2011;165:33-7.

34. Kepes JJ. Transitional cell tumor of the pituitary gland developing from a Rathke's cleft cyst. Cancer. 1978;41:337-43.

35. Trokoudes KM, Walfish PG, Holgate RC, Pritzker KP, Schwartz ML, Kovacs K. Sellar enlargement with hyperprolactinemia and a Rathke's pouch cyst. JAMA. 1978;240:471-3.

36. Ikeda $\mathrm{H}$, Ohhashi $\mathrm{G}$. Demonstration of high coincidence of pituitary adenoma in patients with ruptured Rathke's cleft cyst: Results of a prospective study. Clin Neurol Neurosurg. 2015; 139:144-151. 